\title{
Changes of the Total Lipid and Omega-3 Fatty Acid Contents in two Microalgae Dunaliella Salina and Chlorella Vulgaris Under Salt Stress
}

\author{
Sharare Rismani ${ }^{1}$, Mansour Shariati ${ }^{{ }^{*}}$ \\ ${ }^{1}$ Dept. of Biology, University of Isfahan, 8174673441, Isfahan, Iran.
}

\begin{abstract}
Effect of salt stress on biomass, cell number, contents of total lipid, omega-3 fatty acids, including ALA (Alpha Linolenic Acid), EPA (Eicosapentaenoic Acid) and DHA (Docosahexaenoic Acid) and their biosynthetic pathway intermediates (palmitic acid, stearic acid, oleic acid and linoleic acid) of two microalgae Dunaliella salina and Chlorella vulgaris were investigated. Dilution stress from 1.5 to $0.5 \mathrm{M} \mathrm{NaCl}$ and salt stress from 1.5 to $3 \mathrm{M} \mathrm{NaCl}$ were incorporated into the D. salina medium. Salt stress of $200 \mathrm{mM} \mathrm{NaCl}$ was also applied to C. vulgaris culture. Results indicated that increasing salt concentration resulted in the reduced growth rate of $C$. vulgaris and substantial increase of the total lipid content in both species. Proper growth rate of D. salina observed at $1.5 \mathrm{M}$ of $\mathrm{NaCl}$, but higher and lower concentrations led to the decreased growth rate of D. salina. In addition, considerable increase in the degree of fatty acid unsaturation and thereby the total omega 3 fatty acid content of D. salina was observed under salt stress. Salt stress had little positive effect on the amount of total omega-3 fatty acid of $C$. vulgaris due to the slight increase of the EPA content. Results showed that salt stress is an effective way for enhancing the total lipid and omega-3 fatty acid production in D. salina.
\end{abstract}

Key words: Dunaliella; Chlorella; Salt stress; Lipid; Omega-3

*Author for correspondence: mansour_shariati@yahoo.com 


\section{INTRODUCTION}

One of the most important components of cells is lipids. They are essential for storing energy ${ }^{1}$. Microalgae such as Dunaliella, Chlorella and Spirulina are rich sources of lipid and PUFAs (Poly Unsaturated Fatty Acids) such as ALA (Alpha

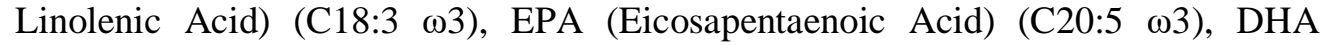

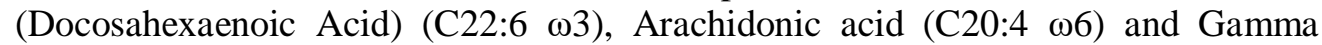
linolenic acid $(\mathrm{C} 18: 3 \omega 6)^{2,3}$. These algae are capable of rapid growth, high biomass production and have simple nutritional requirements. In recent years, many studies were undertaken to evaluate the effect of various treatments on microalgal lipid quantity and quality in particular, omega-3 fatty acids including ALA, EPA, and DHA $^{4-6}$. As, EPA and DHA are important for reducing blood cholesterol, prevention of cardiovascular disease, obesity, depression and other disorders ${ }^{7-9}$, these compounds could be used for improving human health. Recently, high amount of lipid extracted from microalgae has been considered for converting into biodiesel ${ }^{10}$. There are some reports that conditions like salt stress, nutrient limitation, high irradiance and temperature affect the lipid contents and fatty acid compositions in microalga ${ }^{11-13}$. Microalgae suggested as a new source of omega-3 fatty acids. Fish is the current source of omega-3 which is an inadequate source for increasing omega-3 fatty acid demands ${ }^{14}$. On the other hand, microalgal omega- 3 fatty acids have no contaminations by heavy metals and other poisons ${ }^{15}$. It is worth noting that omega-3 fatty acids of fish oil fundamentally derived from microalgae which eaten by fish ${ }^{16}$. In this viewpoint, microalgae are more suitable source than fish for EPA and DHA provision. Dunaliella is a halotolerant, unicellular green alga, which does not have cell wall ${ }^{17}$. Therefore, its lipid could be extracted easily. Moreover, it can grow to high biomass concentration and survive under environmental stresses such as high salt concentration of sea water ${ }^{18}$. Chlorella is a unicellular, fresh water alga, which has a cell wall and is able to produce high lipid amounts ${ }^{19}$. Chlorella has simple growth conditions and limited nutritional demands. Furthermore, it can produce high amounts of biomass in a short time ${ }^{2}$. Salt stress is one of the most important stresses that microalgae subjected to it ${ }^{21}$. The present study was performed to test the effect of different concentrations of $\mathrm{NaCl}$ on the growth rate and amounts of total lipid, omega-3 fatty acids and their biosynthetic intermediates in Dunaliella salina and Chlorella vulgaris.

\section{MATERIAL AND METHODS}

\section{Algae source}

Microalgae Dunaliella salina UTEX 200 and Chlorella vulgaris UTEX 265 were obtained from the algae collection held by the University of Texas.

\section{Algal culture conditions}

The modified Johnson's medium ${ }^{22}$ was used for the cultivation of D. salina. C. vulgaris was grown in the modified Basal medium ${ }^{23}$. The cultures prepared in separated $3000 \mathrm{ml}$ cotton plugged Erlenmeyer flasks containing $1000 \mathrm{ml}$ of sterilized medium supplemented with the various $\mathrm{NaCl}$ concentrations. The $\mathrm{pH}$ of media was adjusted to 7-7.5. D. salina cells cultured in the concentration of $1.5 \mathrm{M} \mathrm{NaCl}$ as control. The dilution stress from 1.5 to $0.5 \mathrm{M} \mathrm{NaCl}$ was applied by adding the required amount of Johnson's medium without $\mathrm{NaCl}$ to $D$. salina cells grown in 1.5 $\mathrm{M}$ of medium as control. In contrast, the salt stress from 1.5 to $3 \mathrm{M} \mathrm{NaCl}$, was applied by adding appropriate amount of $4.5 \mathrm{M} \mathrm{NaCl}$ of Johnson's medium to the control cultures of $D$. salina to obtain final concentration of $3 \mathrm{M} \mathrm{NaCl}$. As $D$. salina 
Effect of salinity on lipid in two microalgae

is a halotolerant microalga but $C$. vulgaris is not, the $\mathrm{NaCl}$ concentrations used for salt stress in D. salina cultures are lethal for $C$. vulgaris. Accordingly, the most suitable concentration of $\mathrm{NaCl}$ for salt stress in $C$. vulgaris determined by applying concentrations ranging from 50 to $600 \mathrm{mM}$ of $\mathrm{NaCl}$. As the severe growth reduction of $C$. vulgaris cells occurred in 300 and $400 \mathrm{mM}$ and the death of them observed in 600 and $700 \mathrm{mM}$, therefore, $200 \mathrm{mM}$ concentration preferred for $\mathrm{NaCl}$ treatment of C. vulgaris. All the cell inoculations and stresses were applied in the aseptic conditions into the each Erlenmeyer flask to nearly reach the initial cell number of $3.1 \times 10^{6}$ per $\mathrm{ml}$ in $D$. salina and $1.8 \times 10^{6}$ per $\mathrm{ml}$ in $C$. vulgaris cultures. The cultures were illuminated using fluorescent lamps with $100 \mu \mathrm{mol}$ photon $\mathrm{m}^{-2} \mathrm{~s}^{-1}$ intensity in the light cycle of $16 \mathrm{~h}$ light/ $8 \mathrm{~h}$ dark. The algae cultures were maintained in the controlled condition with orbital shaking at $100 \mathrm{RPM}$ and $25 \pm 1^{\circ} \mathrm{C}$ for the 15 days period. The algae samples were taken on the days of $0,5,10$ and 15 to estimate the variation of cell number, dry weight and total lipid, omega-3 fatty acids and their biosynthetic intermediates contents of both species under salt stress. All the experiments were performed in three replicates.

\section{Algae growth assessment}

The cell number was calculated ${ }^{24}$ with the hemocytometer using the light microscope.

\section{Biomass dry weight assay}

$100 \mathrm{ml}$ of the culture was sampled and centrifuged at $1000 \mathrm{~g}$ for 15 minutes, which was led to the formation of two phases. The upper phase as supernatant was removed and the lower phase as the sedimented cells was dried at the room temperature. For C. vulgaris cells treated with $\mathrm{NaCl}$, the pellet was washed gently by Basal medium containing no $\mathrm{NaCl}$. The suspension was centrifuged again and the pellet was dried and then weighted. As D. salina has no cell wall, washing the cells with distilled water or medium containing no $\mathrm{NaCl}$ led to swelling cell and membrane disruption. Therefore, the weight of the $\mathrm{NaCl}$ residue in the pellet was calculated and then subtracted from the total weight for measuring the exact biomass dry weight.

\section{Lipid extraction}

The biomass was obtained through the centrifugation of $100 \mathrm{ml}$ of the culture at $1000 \mathrm{~g}$ for 15 minutes. The lipids extracted according to the Bligh and Dyer method

${ }^{25}$. Chloroform and methanol added to the biomass in two steps and mixed well. The cell disruption was performed using a homogenizer (Heidolph DIAX 900, Germany). Afterward, $1 \% \mathrm{NaCl}$ added to obtain the ratio of 2 chloroform: 1 methanol: $1 \mathrm{NaCl}$, and then, was centrifuged at $1000 \mathrm{~g}$ for 10 minutes. The lower phase containing all the lipids and chloroform was separated and desiccated under the nitrogen gas. The remained lipids were weighed and maintained at $-20^{\circ} \mathrm{C}$. All the materials were provided by Merck Corporation.

\section{Fatty acid analysis}

The extracted lipids were transmethylated through the Ortega et al. method ${ }^{26}$. The obtained methyl esters of fatty acids analyzed with the gas chromatograph (Agilent 19091J-413, USA) equipped with the FID detector and the column (HP-5) with a 30 $\mathrm{m}$ long, $0.32 \mathrm{~mm}$ inside diameter and $0.25 \mu \mathrm{m}$ stationary phase thickness. Helium was utilized as the carrier gas. The initial column temperature was $60^{\circ} \mathrm{C}$. The detector and injector temperatures were $250^{\circ} \mathrm{C}$. The transmethylated fatty acids were injected into the gas chromatograph in the volume of $1 \mu \mathrm{L}$ and the 1:10 ratio in the 
split manner. Types and amounts of fatty acids consist of ALA, EPA, DHA, palmitic acid, stearic acid, oleic acid and linoleic acid were identified using the chromatogram of transmethylated samples compared with that of fatty acid standard (Sigma Chemical Co).

\section{Statistical analysis}

In all experiments, statistical comparisons performed using ANOVA with Duncan test at $\mathrm{P}<0.05$.

\section{RESULTS}

Effect of salt stress on the cell number and biomass dry weight

As observed in Fig. 1A and C, the cell number and biomass dry weight of D. salina was decreased by the changing $\mathrm{NaCl}$ concentration in the medium from 1.5 (control) to $0.5 \mathrm{M}$ and 1.5 to $3 \mathrm{M}$. The optimum cell division and biomass dry weight obtained at $1.5 \mathrm{M}$, which is respectively equivalent to $83 \times 10^{5}$ cell. ml $^{-1}$ and $12 \times 10^{2} \mathrm{mg} . \mathrm{L}^{-1}$ on the $15^{\text {th }}$ day. The cell number and biomass dry weight values of $C$. vulgaris significantly decreased to $11 \times 10^{5} \mathrm{cell}^{\mathrm{ml}} \mathrm{m}^{-1}$ and $14 \times 10^{2} \mathrm{mg} \cdot \mathrm{L}^{-1}$ respectively at 200 $\mathrm{mM}$ of $\mathrm{NaCl}$ in the medium as compared to control (Fig. 1B and D). In general, cell division and biomass production in $C$. vulgaris is higher than $D$. salina.
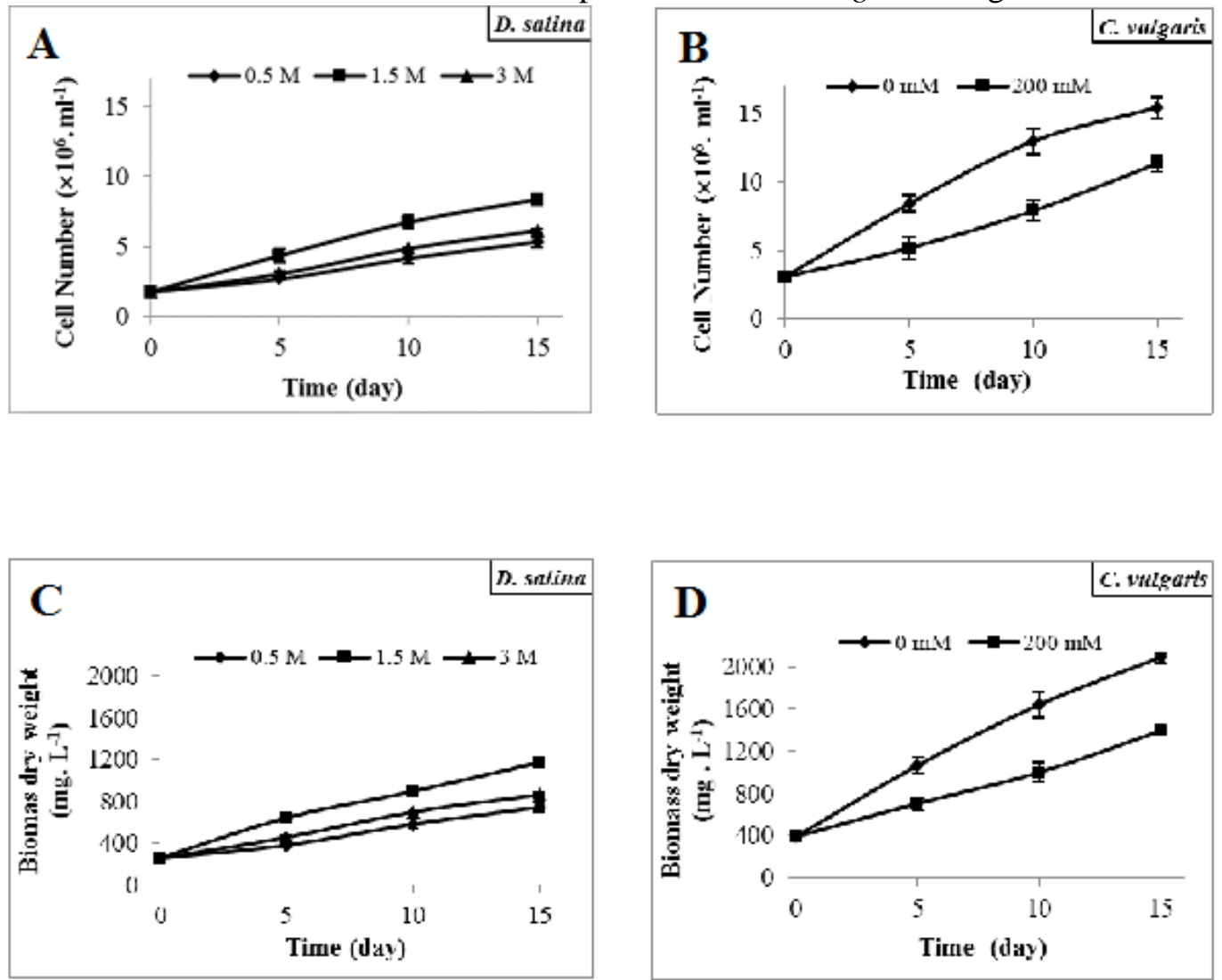

Figure 1- Effect of salt stress on the cell numbers and biomass dry weight per unit of volume in D. salina (A, C) and $C$. vulgaris $(\mathrm{B}, \mathrm{D})$. The data are expressed as mean \pm standard deviation of three replicates.

\section{Effect of salt stress on the total lipid content}

According to Fig. 2A, the highest amount of total lipid was obtained at $3 \mathrm{M} \mathrm{NaCl}$ in D. salina cells. This was nearly equivalent to $143 \mathrm{mg}$. $\mathrm{g} \mathrm{dw}^{-1}$ on $15^{\text {th }}$ day, which was about $14 \%$ more than the start of the experiment and $43 \%$ higher than the control. There was no significant difference between the total lipid content of $3 \mathrm{M} \mathrm{NaCl}$ on 
Effect of salinity on lipid in two microalgae

days 5, 10 and 15 . When the $\mathrm{NaCl}$ concentration was $1.5 \mathrm{M}$ (control), a $21 \%$ decrease was observed until the $15^{\text {th }}$ day, whereas dilution stress from 1.5 to $0.5 \mathrm{M}$ was led to $16 \%$ decrease as compared to the control and $33 \%$ reduction compared with the commencement of the experiment (Fig. 2A). While, $200 \mathrm{mM} \mathrm{NaCl}$ in $C$. vulgaris media, resulted in a $82 \%$ enhancement in the total lipid production (154 mg. $\mathrm{g} \mathrm{dw}-1$ ) compared with no $\mathrm{NaCl}$ in the medium (control) on the $15^{\text {th }}$ day (Fig. 2B).
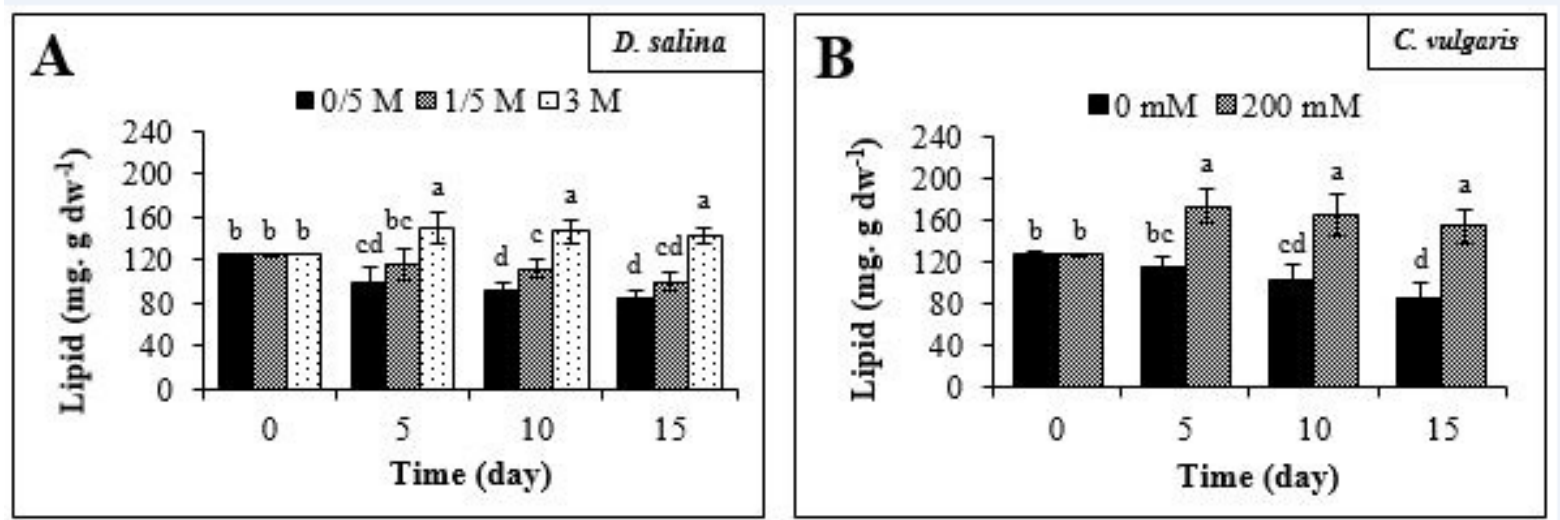

Figure 2- Effect of salt stress on the total lipid content per unit of biomass dry weight in D. salina (A) and C. vulgaris $(\mathrm{B})$. The data are expressed as mean \pm standard deviation of three replicates. Different letters indicate significant differences between various concentrations in each species at $\mathrm{p}<0.05$ according to Duncan test.

\section{Effect of salt stress on the ALA content}

The $D$. salina cells grown at the $\mathrm{NaCl}$ concentration higher than $1.5 \mathrm{M}$ produced the highest yield of ALA, which increased $70 \%$ after 15 days and also showed $66 \%$ as compared to the control (Fig. 3A). While, the minimum yield of ALA occurred in the culture with $0.5 \mathrm{M}$ of $\mathrm{NaCl}$, which indicated about $44 \%$ decrease in comparison with the beginning of the experiment and decreased $46 \%$ as compared to the control $(1.5 \mathrm{M})$ on day 15 . As presented in Fig. 3B, in C. vulgaris cultures, the higher ALA content corresponded to $200 \mathrm{mM}$ of $\mathrm{NaCl}$, which increased about $154 \%$ as compared with the control and $75 \%$ after 15 days.

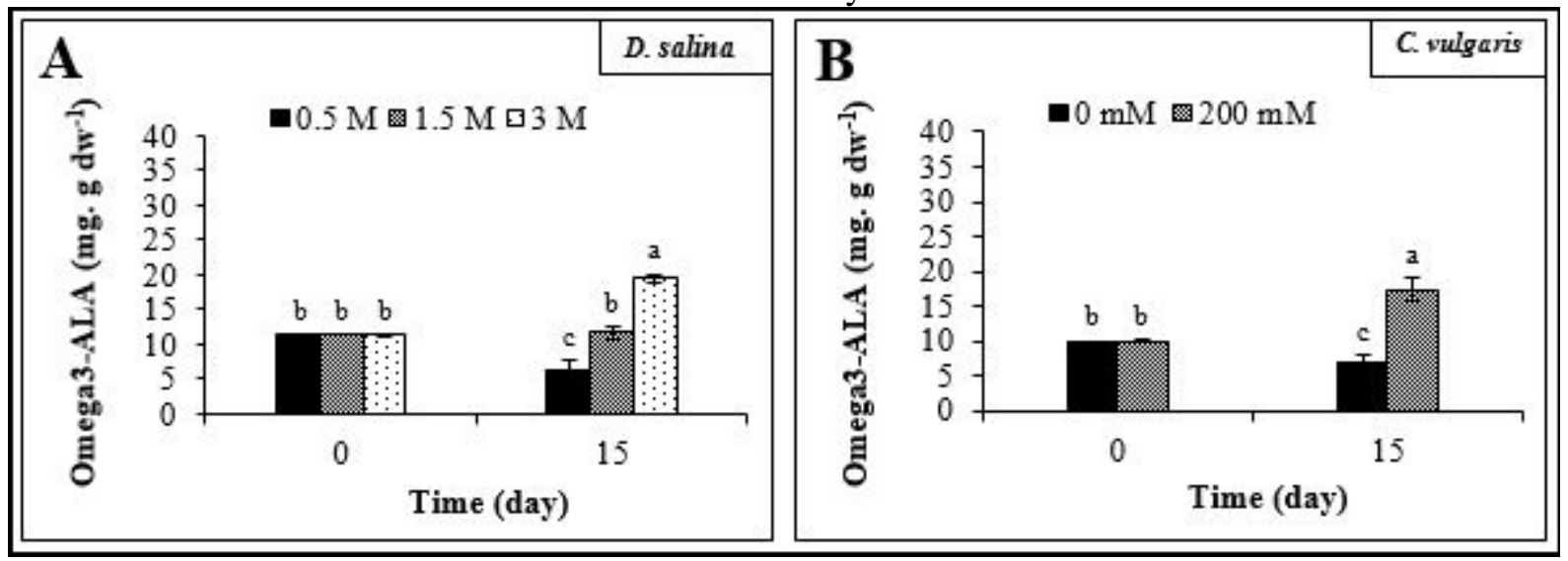

Figure 3- Effect of salt stress on the ALA content per unit of biomass dry weight in $D$. salina (A) and C. vulgaris (B). The data are expressed as mean \pm standard deviation of three replicates. Different letters indicate significant differences between various concentrations in each species at $\mathrm{p}<0.05$ according to Duncan test.

\section{Effect of salt stress on the EPA content}

As shown in Fig. 4A, hyper osmotic shock in D. salina culture brought about the 92\% increase in EPA value in comparison with the control and enhanced $60 \%$ as compared with day 0. Additionally, hypo osmotic shock was led to the lowest EPA value on day 15. As well as, the higher EPA production occurred at $200 \mathrm{mM}$ of $\mathrm{NaCl}$ 
in $C$. vulgaris, which enhanced the EPA content about $76 \%$ compared to day 0 and $136 \%$ as compared with the control 15 days after commencement of the experiment (Fig. 4B).
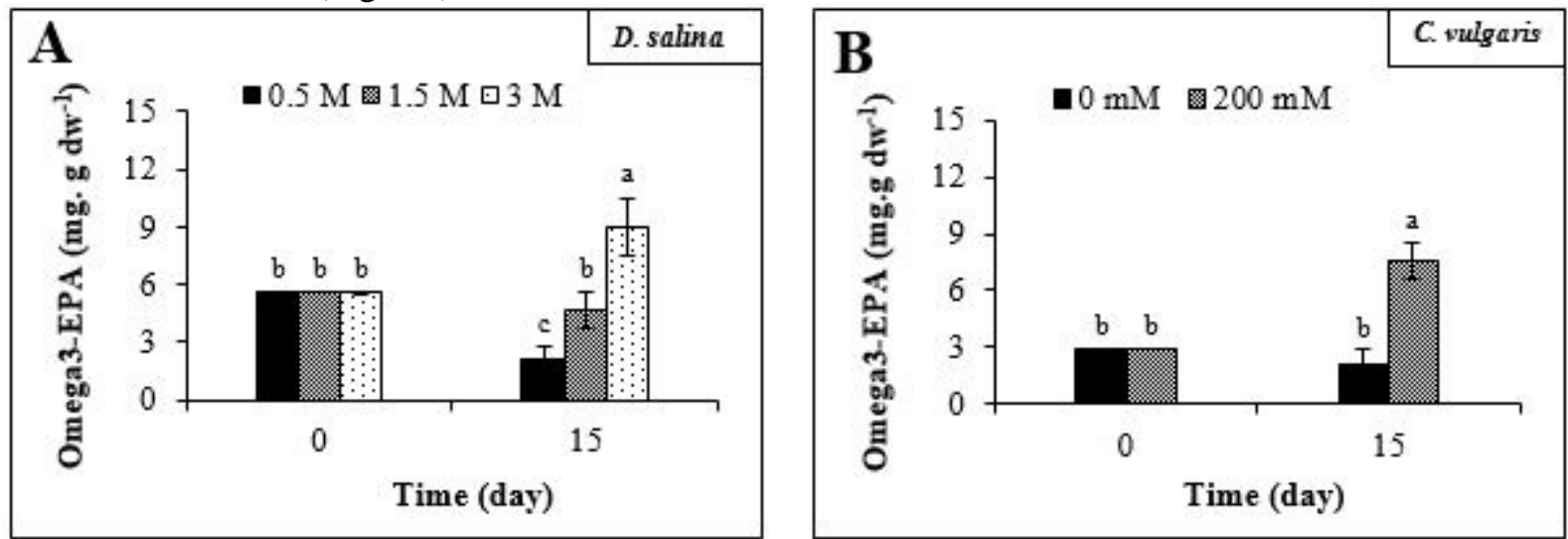

Figure 4 - Effect of salt stress on the EPA content per unit of biomass dry weight in D. salina (A) and C. vulgaris (B). The data are expressed as mean \pm standard deviation of three replicates. Different letters indicate significant differences between various concentrations in each species at $\mathrm{p}<0.05$ according to Duncan test.

\section{Effect of salt stress on the DHA content}

As shown in Fig. 5A, by adding $\mathrm{NaCl}$ to the control medium from $1.5 \mathrm{M}$ to $3 \mathrm{M}$, significantly enhanced the DHA content of $D$. salina, which is equivalent to about $22 \%$ in comparison with day 0 and $309 \%$ compared with the control on the $15^{\text {th }}$ day. Conversely, by diluting the control medium $(1.5 \mathrm{M})$ to $0.5 \mathrm{M}$, considerably reduced the DHA content insofar as not detected on day 15 . The DHA value of $C$. vulgaris was not influenced by $200 \mathrm{mM}$ concentration of $\mathrm{NaCl}$ (Fig. 5B).
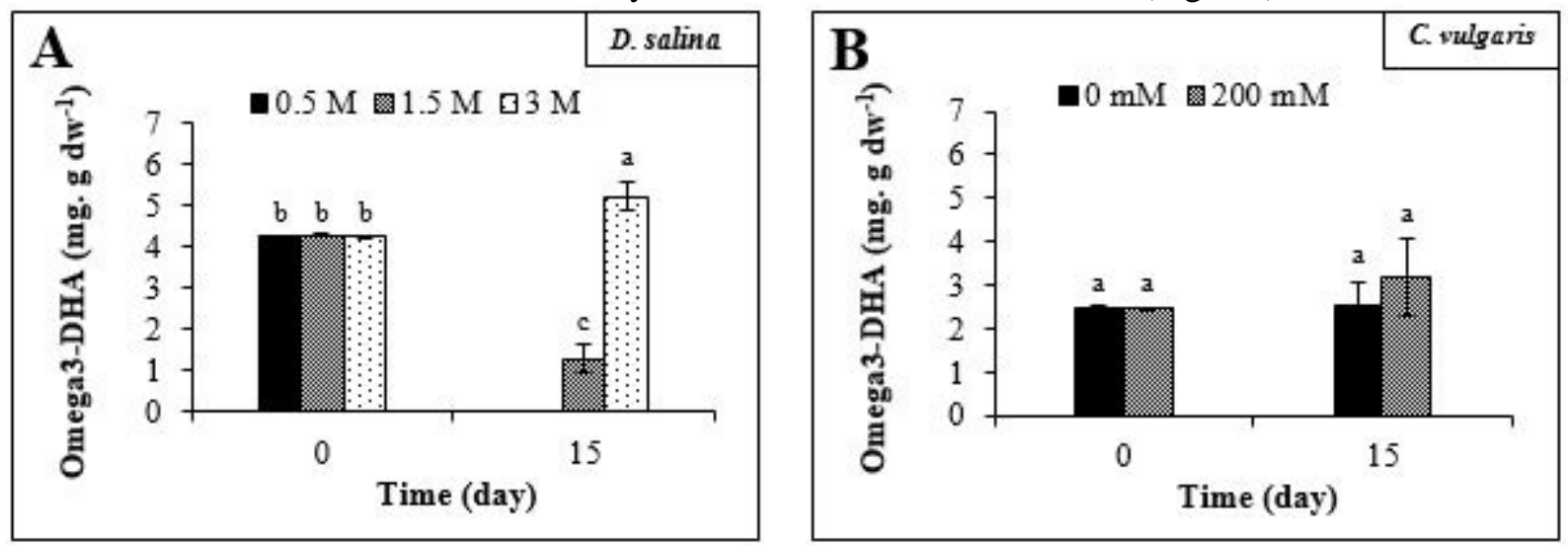

Figure 5 - Effect of salt stress on the DHA content per unit of biomass dry weight in $D$. salina (A) and C. vulgaris (B). The data are expressed as mean \pm standard deviation of three replicates. Different letters indicate significant differences between various concentrations in each species at $\mathrm{p}<0.05$ according to Duncan test.

\section{Effect of salt stress on the total omega-3 content}

As presented in Fig. 6A, the total omega-3 fatty acid content in D. salina was enhanced to $33.675 \mathrm{mg}$. $\mathrm{g} \mathrm{dw}^{-1}$ with the increase of salinity to $3 \mathrm{M}$ which is generally about $90 \%$. The $52 \%$ decrease was observed when the salinity decreased to $0.5 \mathrm{M}$ in comparison to the control on the $15^{\text {th }}$ day. As well as, the total omega- 3 content increased 58\% compared to day 0 under hyper osmotic shock. As illustrated in Fig. $6 \mathrm{~B}$, the $\mathrm{NaCl}$ concentration of $200 \mathrm{mM}$ caused the increase of the total omega-3 value to $25.67 \mathrm{mg}$. $\mathrm{g} \mathrm{dw}^{-1}$ in $C$. vulgaris, which is equivalent to $123 \%$ as compared with the control on day 15 . Salt stress increased the total omega- 3 content about $69 \%$ after 15 days as well. 

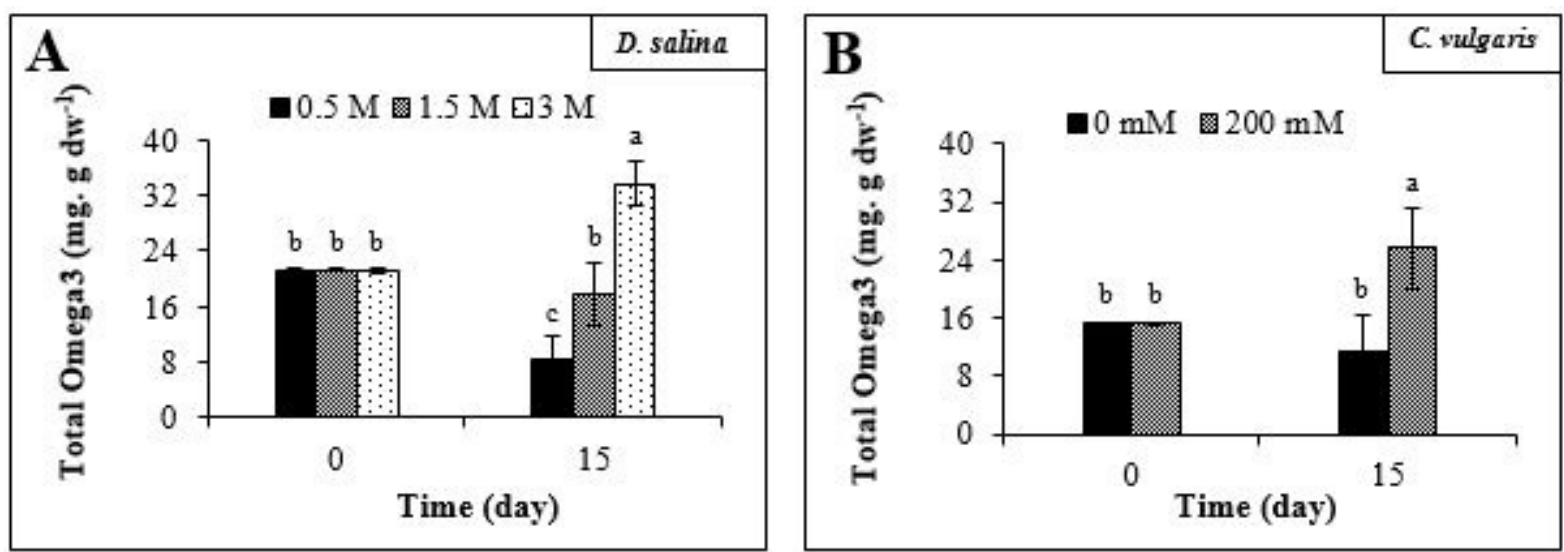

Figure 6- Effect of salt stress on the total omega-3 fatty acid content per unit of biomass dry weight in D. salina (A) and C. vulgaris (B). The data are expressed as mean \pm standard deviation of three replicates. Different letters indicate significant differences between various concentrations in each species at $\mathrm{p}<0.05$ according to Duncan test.

\section{Quantitative analysis of fatty acid methyl ester profiles (percent of total fatty acid) under salt stress}

As illustrated in Fig. 7A, B and C, the EPA and DHA exist in the trace amounts in D. salina and $C$. vulgaris. The $3 \mathrm{M}$ concentration of $\mathrm{NaCl}$, simultaneously increased the percentage of the ALA, EPA, DHA (omega-3 types) and some omega-3 fatty acid biosynthetic intermediates including the oleic acid and stearic acid amounts of D. salina. While, the linoleic acid and palmitic acid percentages decreased on 15 days after supplementation (Fig. 7A). Moreover, at $0.5 \mathrm{M}$ of $\mathrm{NaCl}$, ALA, EPA, DHA and total omega- 3 contents were markedly decreased on the $15^{\text {th }}$ day of cultivation so that DHA was not detected. As well as, the oleic acid content of D. salina cells was decreased noticeably and stearic acid, linoleic acid and palmitic acid of them was increased (Fig. 7B). Although, $200 \mathrm{mM}$ of $\mathrm{NaCl}$ had no significant effect on the percentage of DHA of $C$. vulgaris on the $15^{\text {th }}$ day, increased both ALA and EPA percentages which, accompanied by the increase in the total omega-3 fatty acid percentage. Furthermore, increasing $\mathrm{NaCl}$ concentration resulted in the concurrent increase of the palmitic acid, stearic acid, and linoleic acid amounts but decreased the oleic acid percentage (Fig. 7C). 


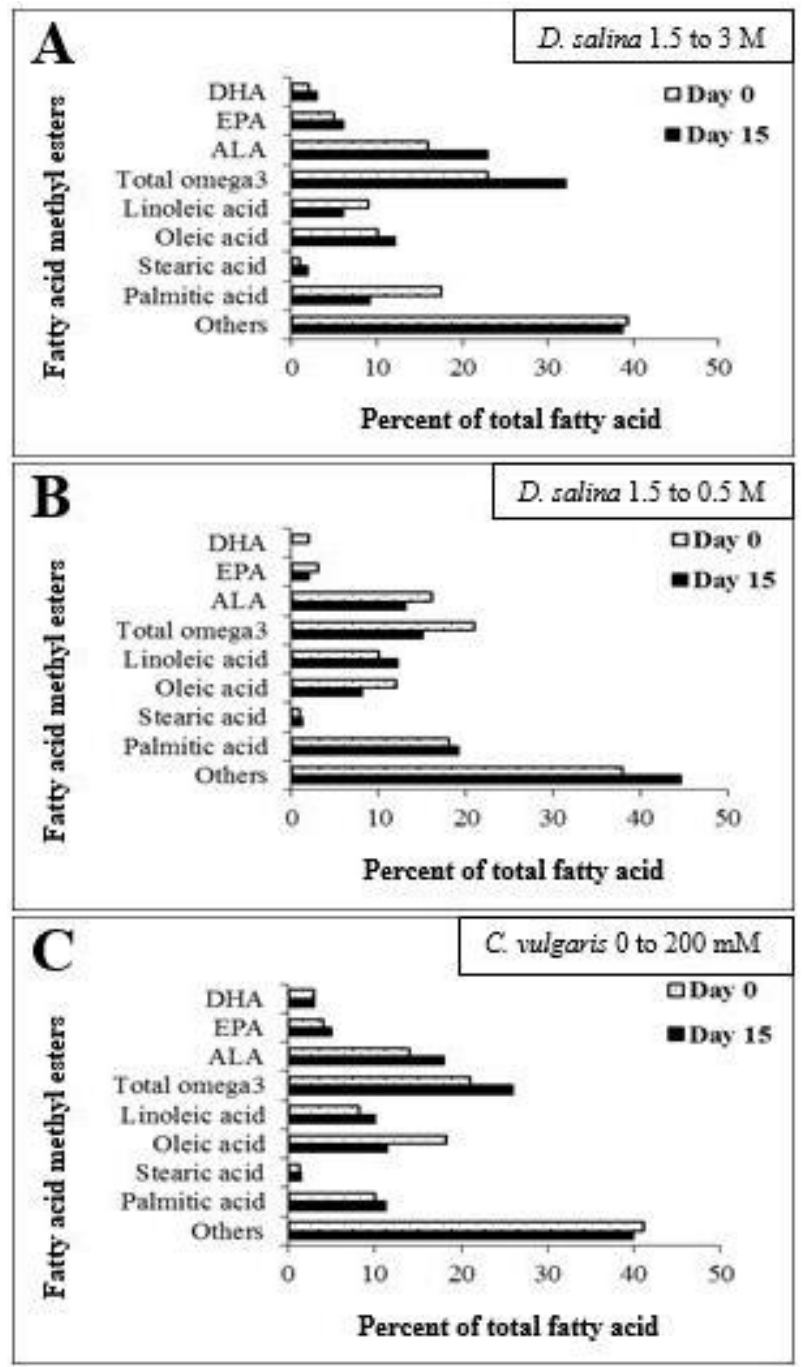

Figure 7- Quantitative analysis of fatty acid methyl ester profiles, in terms of fatty acids (percent of total fatty acid) in D. salina under hyper osmotic stress from 1.5 to $3 \mathrm{M}$ of $\mathrm{NaCl}$ (A), hypo osmotic stress from 1.5 to $0.5 \mathrm{M}$ of $\mathrm{NaCl}$ (B) and C. vulgaris under salt stress of $200 \mathrm{mM} \mathrm{NaCl}(\mathrm{C})$. The data are expressed as means of three replicates.

\section{DISCUSSION}

The results of the present study clearly indicated that the proper growth of $D$. salina merely occurred at the $\mathrm{NaCl}$ concentration of $1.5 \mathrm{M}$ but lower or higher $\mathrm{NaCl}$ concentrations than $1.5 \mathrm{M}$ inhibited cell growth. There are some reports that the increasing $\mathrm{NaCl}$ concentration, reduced the growth rate of $D$. salina while, increased its glycerol content ${ }^{27}$. It appears that the part of metabolic energy presumably expended in producing glycerol caused the decreased growth ${ }^{28}$. The growth of $C$. vulgaris also decreased under salt stress. It has been reported that some organic osmolytes e.g. proline accumulates in expense of metabolic energy in some species of chlorophyceae family such as Chlorella under salt stress ${ }^{21}$. It seems that such mechanism resulted in the reduced growth of $C$. vulgaris. Results suggest that the high $\mathrm{NaCl}$ concentration led to the enhancement in the lipid production of $D$. salina, despite of the reduction of cell number. Conversely, the low $\mathrm{NaCl}$ concentration decreased its lipid pool. As well as, the increase of lipid production observed in the cultures of $C$. vulgaris under salt stress. It seems that increase of lipid content is an adaptive response to salt stress, which is probably due to glycerol production as an organic osmolyte and fatty acid sources. However, relationship between $\mathrm{NaCl}$ 
Effect of salinity on lipid in two microalgae

concentration and lipid accumulation remains unknown ${ }^{11}$. The increase in the degree of unsaturation and enhancement of the long chain fatty acid contents such as omega-3 types consist of DHA, EPA and specially ALA is probably due to dual role of $\mathrm{NaCl}$ in increase of activity of enzymes responsible for elongation and unsaturation of fatty acids in D. salina in response to salt stress ${ }^{29-31}$. In omega-3 biosynthetic pathway, palmitic acid is converted to stearic acid, oleic acid and linoleic acid respectively. Linoleic acid in turn might be diverted to ALA, EPA and then DHA with elongation and unsaturation performance of special enzymes ${ }^{32}$. It seems that in our experiment, salt stress finally resulted in the decrease in palmitic acid which in turn increased the ALA, EPA and DHA production. Therefore, the considerable decrease in palmitic acid caused the increase in the total omega-3 content. It could be concluded that unsaturation of fatty acids, especially those constituent cell membrane related to their critical role in cell membrane stability and adaptive response to unfavorable environmental conditions such as salt stress ${ }^{31}$. Our investigation in $C$. vulgaris revealed that salt stress, increased the level of ALA and EPA while not affected the DHA content, which resulted in the increase of total omega-3 fatty acid value but not as much as $D$. salina. The increase of some omega3 types such as ALA and EPA contents was higher in D. salina. The increase of EPA content has been reported in several microalgae, including Nitzchia laevis and Chlorella minutissima under salt stress ${ }^{33-34}$. These findings emphasize on similar function of different microalgal species in response to salt stress. It appears that increase of PUFAs like ALA and EPA contents have key role in survival of $D$. salina and $C$. vulgaris under salt stress. Biomass concentration and biosynthesis of lipid and omega-3 of individual cells are both important in affecting total lipid and omega-3 contents of microalgae. In spite of the reduction in cell numbers, increase of the total lipid and mostly total omega- 3 contents was observed in both species, along with the increase of salt concentration in the medium suggesting that lipid metabolism was influenced by salt stress directly.

\section{CONCLUSION}

When, two different types of microalgae, D. salina as a halotolerant and C. vulgaris as a fresh water microalga were subjected to the different intensities of salt stresses, lipid and omega-3 productions were stimulated in both of them. This was higher in D. salina than the other one. D. salina has two special characteristics: non existence of cell wall which made it suitable for easy lipid extraction and high amount of lipid and omega-3 production under salt stress in comparison with $C$. vulgaris. Accordingly, D. salina is preferred for simple obtaining of high lipid amount and its applications for biodiesel and omega-3 (ALA, EPA, DHA) productions in the purpose of reducing environmental pollutions and pharmaceutical consumptions. It is well known that cell population has an important role in biotechnological applications of microalgae. As $D$. salina has a low growth rate in response to salt stress, It suggested that salt stress should be applied after increasing of cell biomass.

\section{ACKNOWLEDGMENT}

This research was supported by the office of Graduate Studies of the University of Isfahan, Isfahan, Iran. The supports of the Plant Stress Center in Excellent (PSCE) of Iran is also acknowledged. We would also like to thank the kind assistance of Dr. Mahdi Kadivar, Department of Food Science, Faculty of Agriculture, Technology University of Isfahan, in the GC analysis of fatty acids. 


\section{REFERENCES}

1- Belitz HD, Grosch I. Food chemistry. second edition. Berlin: Springer-Verlag; 1987.

2- Venugopal V. Marine products for healthcare: functional and bioactive nutraceutical compounds from the ocean. Florida: CRC press; 2008.

3- Powell EE, Hill GA. Economic assessment of an integrated bioethanol biodiesel microbial fuel cell facility utilizing yeast and photosynthetic algae. Chem Eng Res Des. 2009; 87: 1340-1348.

4- Yongmanitchai W, Ward OP. Growth of and omega-3 fatty acid production by Phaeodactylum tricornutum under different culture conditions. Appl Environ Microbiol. 1991; 57: 419-425.

5- Boswell K, Koskelo E, Carl KL, Glaza S, Hensen DJ, Williams KD, et al. Preclinical evaluation of single-cell oils that are highly enriched with arachidonic acid and docosahexaenoic acid. Food Chern Toxicol. 1996; 34: 585-593.

6- Xiaodong D, Yajun L, Xiaowen F. Microalgae: A promising feedstock for biodiesel. Afr J Microbiol Res. 3: 2009; 1008-1014.

7- Frank M, Gibson M, Rosner B. Controlled trial of fish oil for regression of human coronary Atherosclerosis. J Am Coll Cardiol. 1995; 25: 1492-1498.

8- Fontani G, Corradeschi F, Felici A, Alfatti F, Migliorini S, Lodi L. Cognitive and physiological effects of omega-3 polyunsaturated fatty acid supplementation in healthy subjects. Eur J Clin Invest. 2005; 35: 691-699.

9- Buckley JD, Howe PRC. Long-chain omega-3 polyunsaturated fatty acids may be beneficial for reducing obesity - a review. Nutrients. 2010; 2: 1212-1230.

10-Kumar M, Sharma MP. Potential assessment of microalgal oils for biodiesel production: A review. J mater Environ Sci. 2014; 5(3): 757-766.

11-Takagi M, Karseno YT. Effect of salt concentration on intracellular accumulation of lipids and triacylglyceride in marine microalgae Dunaliella cells. J Biosci Bioeng. 2006; 101: 223-226.

12-Rao AR, Dayananda C, Sarada R, Shamala TR, Ravishankar GA. Effect of salinity on growth of green alga Botryococcus braunii and its constituents. Bioresour. Technol. 2007; 98: 560-564.

13-Jang YS, Park J, Choi MS, Choi YJ, Seung DY, Cho JH, et al. Engineering of microorganisms for the production of biofuels and perspectives based on systems metabolic engineering approaches. Biotechnol Adv. 2011; 30: 989-1000.

14-Borowitzka MA. Fats, oils and hydrocarbons. In: Borowitzka MA, Borowitzka LJ, editors. Microalgal biotechnology. Cambridge: Cambridge University Press; 1988. p. 257- 287.

15-Gill I, Valivety R. Polyunsaturated fatty acids. part I: Occurrence, biological activities and applications. Trends Biotechnol. 1997; 15: 401-409.

16-Oren A. A hundred years of Dunaliella research: 1905-2005. Saline Systems. 2005; 1: 114.

17-Wegmann K, Ben-Amotz A, Avron M. Effect of temperature on glycerol retention in the halotolerant algae Dunaliella and Asteromonas. Plant Physiol. 1980; 66: 1196-1197.

18-Kay RA. Microalgae as food and supplement. Crit Rev Food Sci Nutr. 1991; 30: 555-573.

19-Griffithus MJ, Harrison STL. Lipid productivity as a key characteristic for choosing algal species for biodiesel production. J Appl Phycol. 2009; 29: 493-507.

20-Kirst GO. Salinity tolerance of eukaryotic marine algae. Annu Rev Plant Physiol Plant Mol Biol. 1989; 40: 21-53.

21-Johnson MK, Johnson EJ, Mc Elroy RD, Speer HL, Bruff BS. Effect of salt on the halophilic alga Dunaliella viridis. J Bacteriol. 1968; 95: 1461-1468.

22-Shi XM, Chen F, Yuan JP, Chen H. Heterotrophic product ion of lutein by selected Chlorella strains. J Appl Phycol. 1997; 9: 445-450.

23-Schoen S. Cell counting. In: Lobban CS, Chapmans DJ, Kremer BP editors. Experimental phycology: A Laboratory Manual. Cambridge: Cambridge University Press; 1998. p. 1622. 
Effect of salinity on lipid in two microalgae

24-Bligh EG, Dyer WJ. A rapid method of total lipid extraction and purification. Can J Biochem Physiol. 1959; 37: 911-917.

25-Ortega JA, Lopez-Hernandez HS, Gracia CG, Hill Jr. Lipase-mediated acidolysis of fully hydrogenated soybean oil with conjugated linoleic acid. J Food Sci. 2004; 69: 1-6.

26-Shariati M, Hadi MR. Microalgal biotechnology and bioenergy in Dunaliella. In: Carpi A, editor. Progress in Molecular and Environmental Bioengineering- From Analysis and Modeling to Technology Applications. Crotia: Intech; 2011. p. 483-506.

27-Shariati M, Lilley RMcC. Loss of intracellular glycerol from Dunaliella by electroporation at constant osmotic pressure: subsequent restoration of glycerol content and associated volume changes. Plant Cell Environ. 1944; 17: 1295-1304.

28-Seto A, Wang HL, Hesseltine CW. Culture conditions affect eicosapentaenoic acid content of Chlorella minutissima. J Am Oil Chem Soc. 1984; 61: 892-894.

29-Bellitti IM, Nicolaus B, Lama L, Manca MC, Pagnotta E, Gambacorta A. Lipid profile a useful chemotaxonomic marker for classification of a new cyanobacterium in Spirulina genus. Phytochemistry. 2000; 54: 289-294.

30-Abd El-Baky HH, El Baz FK, El-Baroty GS. Production of Lipids Rich in Omega-3 Fatty Acids from the Halotolerant Alga Dunaliella salina. Biotechnology. 2004; 3: 102-108.

31-Guschina IA, Harwood JL. Lipids and lipid metabolism in eukaryotic algae. Prog Lipid Res. 2006; 45: 160-186.

32-Chen GQ, Jiang Y, Chen F. Salt induced alterations in lipid composition of diatom Nitzschia laevis (Bacillariophyceae) under heterotrophic culture condition. J Phycol. 2008; 44: 1309-1314.

33-Bumbak F, Cook S, Zachleder V, Hauser S, Kovar K. Best practices in heterotrophic high-cell-density microalgal processes: achievements, potential and possible limitations. Appl Microbiol Biotechnol. 2011; 91: 31-46.

34-Sharma KK, Schuhmann H, Schenk PM. High Lipid Induction in Microalgae for Biodiesel Production. Energies. 2012; 5: 1532-1553. 


\section{Erratum}

In Article "Changes of the Total Lipid and Omega-3 Fatty Acid Contents in two Microalgae Dunaliella Salina and Chlorella Vulgaris Under Salt Stress”, with the number of DOI: http://dx.doi.org/10.1590/1678-4324-2017160555, published in journal Brazilian Archives of Biology and Technology, vol. 60, the 01 page.

That read:

"http://dx.doi.org/10.190/1678-4324-2017160555"

Read:

"http://dx.doi.org/10.1590/1678-4324-2017160555" 